Eixo Temático: Relação entre Ciência, Educação e Cultura

ET-05-007

\title{
APLICAÇÃO DE EXPERIMENTOS EM CIÊNCIAS NATURAIS PARA O PROCESSO DE ENSINO E APRENDIZAGEM NAS ESCOLAS BÁSICAS
}

Maria San Miris Lopes de Oliveira, Elivelton Veríssimo de Souza, Karla Euzebio Maria da Silva

Universidade Federal de Pernambuco. Centro de Educação - CE.

http://dx.doi.org/10.21472/congrebio2016.et-05-007

\section{RESUMO}

Sabemos que o ensino por e experimentação exige um preparo do professor para a organização de atividades didáticas assim como, o entender da importância dessa modalidade na formação acadêmica dos estudantes. Esse artigo tem como finalidade discutiratravés das pesquisas realizadas em campo com professores de diferentes níveis de Ensino Fundamental (anos iniciais e anos finais) e de diferentes redes de escolas (pública: municipal e estadual e privada), como é feita a inserção dessas perspectivas teórico-metodológicas em seus planos de aula, a realização do mesmo e quais os motivos para não realização, pontuando assim suas dificuldades. Para tanto, realizamos entrevistas a partir de questões estruturadas e as respostas foram discutidas a partir diferentes referenciais ligados ao Ensino e experimentação. Os resultados apontam ponto de vista do docente associada com as dificuldades e recursos.

Palavras chave: Educação; Aprendizagem; Experimentação.

\section{INTRODUÇÃO}

A educação sofre grandes mudanças com o processo seletivo de modalidades, técnicas a serem utilizados, métodos viáveis ao aluno e a absorção e compreensão do conteúdo programático. Porém, antecedendo qualquer conhecimento que vá transmitido pelo educador, é necessário resgatar pré-concepções desses alunos e a reformulação dessas ideias que possam estar incorretas. Segundo Galiazzi (2001), a introdução de atividades experimentais nas escolas ocorreu há mais de cem anos e tinha como meta melhorar a aprendizagem dos conteúdos científicos e era influenciada pelo trabalho experimental desenvolvido pelas universidades.

Para Giordan (1999), é imputada à experimentação a capacidade de motivar e aumentar o interesse dos alunos em torno de conteúdos escolares. Essa visão é compartilhada por docentes e alunos. Os resultados obtidos serão analisados para a reconstrução de uma antiga concepção. Quando são realizados experimentos, de fácil manuseio, materiais simples e trazendo a atenção e curiosidade no aluno, a aula torna-se didática e a compreensão é alcançada. Onde em alguns casos, o experimento pode ser realizado pelos alunos, com a orientação de um professor deciências.

Os experimentos são feitos de acordo com cada assunto programático, podendo ser inserido no fim das aulas, tendo como avaliação um relatório, podendo ser interdisciplinar feito com o professor de português/produção textual e deve estar imerso no plano de aula e com a ajuda da coordenação da escola. A linguagem das Ciências não é apenas verbal. Afinal, as Ciências Naturais englobam Química, Física, Biologia e Geociências e se utiliza de gráficos, imagens, tabelas entre outros para a compreensão do conhecimento científico. 


\section{OBJETIVOS}

Assim, o presente trabalho objetiva investigar professores de diferentes níveis de ensino a respeito da utilização de práticas experimentais em sala de aula, bem como, inferir a respeito de suas concepções e possíveis dificuldades de implementação.

\section{METODOLOGIA}

As entrevistas foram realizadas para a disciplina Metodologia do Ensino de Biologia 2 ministrada no $2^{\circ}$ período do curso de Licenciatura em Ciências Biológicas pela Universidade Federal de Pernambuco. As respostas foram obtidas em escolas da Região Metropolitana do Recife. Na Escola pública (municipal), Recanto da Arte e do Saber, situada na cidade Olinda, sendo entrevistada a pedagoga. Escola privada Decisão, situada no município Paulista, sendo entrevistado o professor do ensino fundamental II e a escola pública (estadual) Costa Azevedo, situada na Cidade Olinda com o professor do Ensino Médio.

O propósito da entrevista foi analisar o Ensino de Ciências em forma de experimentação, através de perguntas relacionadas a concepções prévias dos alunos e as dificuldades contidas atualmente no ensino por experimentação.

Antes da realização da entrevista, houve um diálogo sobre o propósito do mesmo, com a ênfase de uma pesquisa acadêmica e as informações ditas são verídicas e autorizadas pelos mesmos. Apenas a $3^{\circ}$ professora que pediu o sigilo de informações/dados pessoais. $\mathrm{O}$ questionário realizado foi feitas com as seguintes perguntas:

1. Já lecionou em redepública?

2. Você leva em conta o conhecimento prévio dosalunos

3. Existe a realização de em sala deaula?

4. Existe alguma dificuldade para a realização?Quais?

\section{RESULTADOS E DISCUSSÃO}

As perguntas realizadas tiveram as seguintes informações:

$1^{\text {o }}$ professor: Joyce Lima, 24 anos de idade, Estudante de Pedagogia, na instituição Universidade Federal de Pernambuco, $4^{\circ}$ período. Estagiária na escola pública (municipal) Recanto da Arte e do Saber/Olinda no Ensino Fundamental I.

\section{Já lecionou em redepública?} Olinda”.

“Até agora, só em rede pública. Mas a Rede do Recife, é bem melhor que a rede de

\section{Você leva em conta o conhecimento prévio dosalunos?}

"Deve-se levar em conta o conhecimento prévio dos alunos, até porque o curso de pedagogia atualmente vem tentando quebrar o ensino tradicionalista, no qual só o professor é detentor do saber, levando em conta esse conhecimento prévio é que uma perspectiva construtiva, tornando-se assim uma forma de avaliação".

\section{Existe a realização de experimentos em sala deaula?}

"Sim, é necessário levar os alunos ao conhecimento além da teoria, ou seja, materializar esse conhecimentoajudaos alunos absorver o conteúdo, e só não decorar. Existe 
um teóricochamado Galperin que fala exatamente sobre a importância de materializar e deixar os conteúdos mais palpáveis para os alunos”.

\section{Existe alguma dificuldade para a realização?Quais?}

"A falta de material para trabalhar na escola, onde em alguns momentos o professor tem que tirar o recurso do próprio bolso”.

$2^{\mathbf{0}}$ professor: Bruno Moura, 31 anos de idade, formado há oito anos, pela Universidade Federal Rural de Pernambuco em Física. Começou a lecionar no $3^{\circ}$ período e leciona a 13 anos. Professor no Colégio privado Decisão/Paulista no ensino fundamental II e Ensino médio.

\section{Já lecionou em redepública?}

"Lecionei na rede pública em 2004-2007 (3 anos) a diferença está na cobrança de resultados sobre os alunos para mostrar a eficiência da escola no ensinar. Não se pode negar que o acesso a informações e recursos didáticos facilitam a assimilação e o desempenho tanto dos alunos quanto dosprofessores”.

\section{Você leva em conta o conhecimento prévio dosalunos?}

“Sim, a partir dos conhecimentos é que eu começo a abordar o ter a ser lecionado”.

\section{Existe a realização de experimentos em sala deaula?}

"Atualmente experimentos em sala, são meus maiores aliados no interesse dos alunos na minha disciplina, para assimilação".

\section{Existe alguma dificuldade para a realização?Quais?}

"A dificuldade é abordar a atividade experimental sem que eles tenham o conhecimento prévio e outro fator é a falta de laboratório de física nas unidades de ensino”.

$3^{\mathbf{0}}$ professor: J.M., professor da escola pública (estadual) Costa Azevedo/Olinda no Ensino Médio.

\section{Já lecionou em redepública?}

“Apenas em rede pública”.

\section{Você leva em conta o conhecimento prévio dosalunos?}

"Sim, pois é melhor para desenvolver as aulas, quando o professor leva em conta o conhecimento prévio do aluno, pois juntos podemos reconstruir esse conhecimento, e não frustrar o aluno dizendo que é errado, pois nenhum conhecimento é errado, é apenas mal formulado".

\section{Existe a realização de experimentos em sala deaula?}

“Não realizo experimentos em minhas aulas”. 


\section{Existe alguma dificuldade para a realização?Quais?}

"Devido à falta de material, pois os que são recebidos pelas escolas são poucos - não tem para usar com todas as turmas - há também certa resistência da gestão em relação aos planosde aula interativos, com a antiga coordenação pedagógica era bem melhor a construção dos planos, onde visava aulas dinâmicas, onde os alunos pudessem executar ou ver a execução de tal assunto. Às vezes coloco um filme que nem sempre tem ligação com o conteúdo, pois o acervo didático da escola é escasso.

Pode-se observar que, as linhas de pensamento dos professores são semelhantes em termo de necessidade de realizar e expor aulas com experimentos e a escassez de materiais e a desvalorização desse método. Onde, há o interesse do educador, porém não há incentivos da gestão e meios para que ocorra o processo de ensino e aprendizagem através de experimentos. Onde Giordan (1999) discute que há mais de 2.300 anos, Aristóteles defendia a experiência quando afirmava que "quem possua a noção sem a experiência, e conheça o universal ignorando o particular nele contido, enganar-se-á muitas vezes no tratamento” (p. 43).

\section{CONCLUSÕES}

Portanto, percebeu-se que há uma grande dificuldade em aplicar os objetivos práticos em sala de aula, onde por sua vez, são de extrema importância para o ensino e aprendizagem. Os métodos são tradicionalistas, ficando na base de professor/aluno, deixando-as de ser interativas e dificultando a descoberta e interesse do aluno em tal assunto.

Segundo os ensinamentos de Galiazzi (2000), realizar um experimento seguido de discussão para a Montagem da interpretação dos resultados é uma atividade extremamente rica em termos de aprendizagem.

A utilização do método por experimentação é de fato importante e necessária, segundo os educadores de ciências, não importando os níveis de ensino ou unidades que vão ser ministradas as aulas.

\section{REFERÊNCIAS}

GALIAZZI, M. C. Educar pela pesquisa: espaço de transformação e avanço na formação do professor de Ciências. Porto Alegre: PUCRS, 2000. (Tese de Doutorado em Educação).

GIORDAN, M. O papel da experimentação no ensino de ciências. Química Nova na Escola, n. 10, p. 43-49, 1999. Disponível em: <http://qnesc.sbq.org.br/online/qnesc10/pesquisa.pdf>. Acesso em: 24 mar. 2016. 